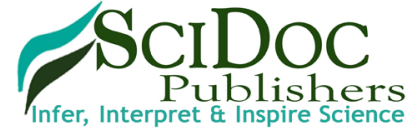

International Journal of Forensic Science \& Pathology (IJFP)

ISSN 2332-287X

\title{
A Review About Child Abuse Crimes Comitted Through Internet In Turkey
}

Review Article

Kara I

Department of Combat Against Cybercrime Police Laboratory, Turkish National Police, Cankaya, Ankara, Turkey.

\section{Abstract}

Child abuse which should be described as all kind of behaviors that negatively affecting child growth and progress has been come across in every culture. The relevance and awareness shown to child abuse has increased despite not yet enough in Turkey recent years. Criminal sanctions and procedural methods of struggling have been regulated either in international law or domestic law in order to combat against abuse of child escalating and spreading day by day. However, new species of offense have traced in parallel with technologic developments, and so, for effective battle would have been made law about satisfying needs. In this study, it has been provided opinion and suggestion about required measures, juridical combating point of offense and its legislative dimension in Turkey.

Keywords: Child Abuse; IT (Information Technology) Crimes; Turkish Law; Criminal.

\section{Introduction}

Sanctions in modern day, rapid improvement of Information Technology (IT) lays the groundwork to commit new offenses alongside providing convenience in all fields of our life. The species of offense perpetually improve based on all innovated instruments of IT, as well. It would be said that, even internet brings new problems along with plenty patterns of behaviors privately in the field of justice [1-3]. Particularly widening of internet and reducing average age of internet user on each passing day, cause to easily commit and escalate child abuse crime [4].

Having complicated reasons and tragic results, child abuse is a serious and extensive trouble such as medicinal, judicial, progressional, psycho-social $[5,6]$. The World Health Organization describes 'child abuse' as the behavior which is acted knowingly or unknowingly by adults, which affect health, physical and psychosocial improvement of child in negative way [7], Child abuse has been classified according four groups as omission, physical, sexual and emotional exploit [8].

In present study, it has been aimed to clarify proposals about manners should have been followed in terms of legal sanction practices in case of committing child abuse crime via IT, besides reviewing its judicial circumstances in Turkey.

\section{It Crimes And Child Sexual Abuse Notions}

In Turkey, IT and Information System (IS) are jurally defined as “a magnetic systems that allow to subject automatic processes after gathering and deploying data" in Turkish Penal Code (TPC) law no. 5237 and justification of article 243. Apart from that, IT and IS doctrinally have various definitions as well as sit out any further legislative regulation. In the most general sense, the word root of IT bases on "Informatique" word received from French to Turkish language. Firstly this word had been called "Enformasyon" as Information, but then, it has been changed as "Bilişim" as Information Technology in Turkish language.

Computer-based Information Technology (CBIS) is the name of socio-technical entirety that constitutes from components which are used to gather, store, process and transmit data thereby benefitting from IT and communication technology. Raising ratio of committed offenses through IT and by this way booming new forms of offense have increased the significance of IT on investigating and enlightening offenses [9].

Child sexual abuse is a fundamental public health matter. Sexual exploited is an adult to use children as a means of own sexual appetite and necessity [10]. Exploit and omission are not not only a

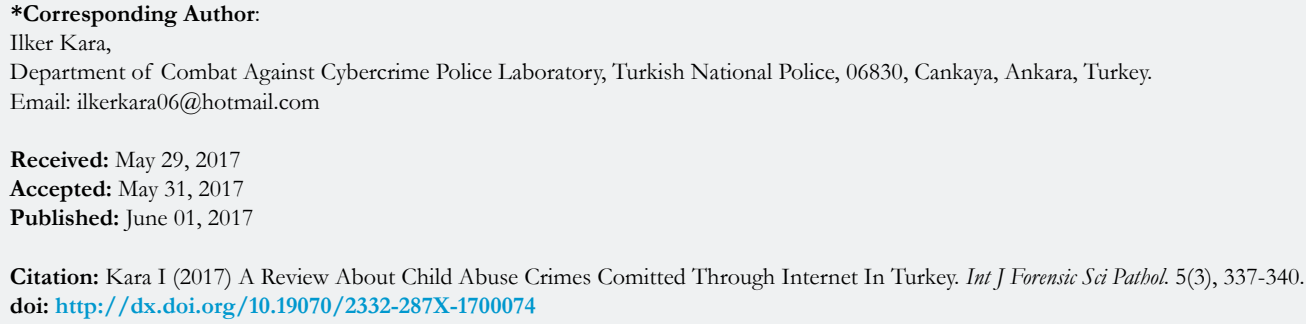

Copyright: Kara $\mathbf{I}^{\circ}$ 2017. This is an open-access article distributed under the terms of the Creative Commons Attribution License, which permits unrestricted use, distribution and reproduction in any medium, provided the original author and source are credited. 
public health matter that adversely influence parents but also affect to commune, social institutes, judicial and education systems and business world [11]. Rapid developments of IT also provide facilities to form new species of offense for offender and to give rise to easily commit an offense at the side of gaining advantages in every sphere of our life.

The optimum measure to eliminate sexual abuse is to proactively prevent offense before the fact. To this end, criminal sections and procedural methods of combatting against these kind of offenses are put in order either in international law or domestic law. However, current regulations are obvious to not fulfill needs to prevent emerging new species of offense as parallel to growing technology and effectively to struggle against offenses. Another matter also is to fight against an international issue as child abuse with national orders. Briefly, "international issues never be solved by national methods". Therefore, the studies which will abolish problems or will reduce lowest level by using media tools have been essential associated with truth of requiring regulations that should be offered international new and distinctive remedies in order to be able to meet today's requirements with reconsidering current regulations.

\section{Results and Discussion}

\section{Child Abuse Crime In Terms Of Turkish Penal Code}

Particularly "child sexual abuse on internet" crime remarkably has a tendency to increase as well as inclination of commit an offense to be a socio-economic phenomenon in Turkish community.

On Figure 1. shown the diagram of child sexual abuse crimes changing between year 2015 and 2016 in Turkey. Offense tendency has shown a huge escalation on child abuse crime even as the other offense fields in Turkey. As it seen on Figure 1., child pornography offense has increased in rate $\% 129$ percent, while child abuse crime shows the highest escalation with ratio $\% 133$ percent through IT crimes between 2015-2016. The first fact at this escalation is to imprecisely using internet, specifically social media web sites, by each part of community.

The members of social networks not only could reach all profiles and their sharing but also the users might attain the existed users on friend lists of another users with their knowledges and data. This virtual platform is used in order to finding friends, inspecting and observing, sharing, playing game, being organize, political activity, e-commerce, sexuality and reporting [6].

Having determinations with regards to parents and children on a report prepared by IT security company Norton with reference of 13.000 participants who are among ages of 18 to 65 from 24 countries in 2016, provide at below [12];

- $\% 6$ percent of families have oblivious of what their children do online environment.

- Nevertheless according to children same ratio is $\% 17$ percent.

- $\% 12$ percent of children try to access mature contents while their parents not be around.

- $\% 23$ percent of families state that their children change web page when they awaken to

- Monitored by parents.

- $\% 40$ percent of children express that they stop internet explore activities while parents.

- Surveillance them.

In Turkey much-debated using social media at a young age triggers a proper ground in particular for child abuse. In this framework, social and individual measures have to be taken about misusing of social media. This obligation might be priority issue to be solved by governments for healthy generations. To the end of the rising of social media consumption, also safety of making friendship on social network should be interrogated while these friendship bond increase. Expressly, children being in the dark about communicating with unknown people or perceiving as a game, inevitably confronts of us to be exploited of them.

With current and in the future form of legislative regulations could be a measure about child abuse, yet is not be lasting solution alone. Awareness of parents and the governmental policy initially take a place in this case. Being family to rise awareness their children and be provided training program by the authorities is the core elements to deliberate against unknown people who wants to communicate them.

In recent years, the awareness of child abuse has been raised

Figure 1. Changing diagram of Child sexual abuse in 2015-2016, General Directorate of Security, Branch Office of Combat Against Cybercrime Police Laboratory (personal communication).

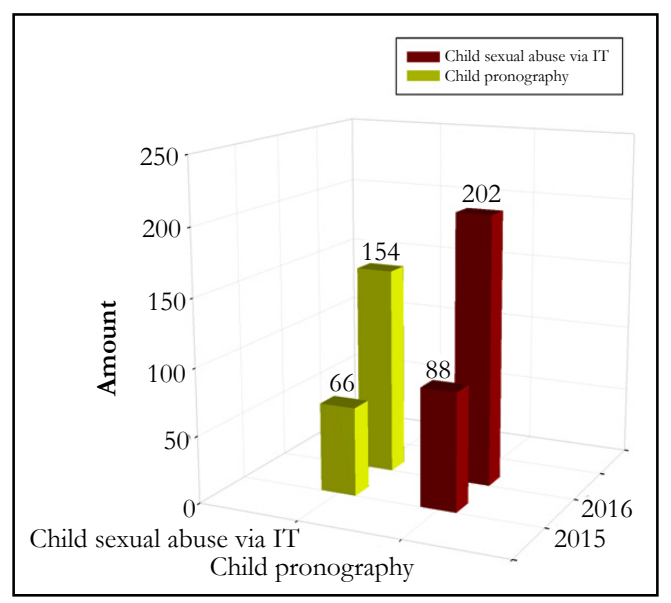


as well as it is not optimum level in Turkey. In TPC, article 103 and subclaus 2 under caption "child sexual abuse", as "all kind of sexual attempt against children who are under age of fifteen or against those attained the age of fifteen but lack of ability to understand the legal consequences of such act". not to look for condition of physical contact, and be described as all kind of sexual behaviors which is done against the children under age of fifteen. In TPC, article 105 subclause 1 as " Anyone who sexually harasses a person, upon a complaint filed by the victim, shall be imprisoned for a term of from three months to two years or a judicial fine". (Amendment inscription: 6545-18.6.2014/m.61 ). "Anyone who sexually harasses a child, shall be imprisoned for a term of from six months to three years or a judicial fine". having legislative regulations to combat against child abuse and omission of child are not capable in order to effective struggling against these offenses and increasing awareness in parallel to technological developments.

In this context, TPC article 226 and subclause 3 under caption "obscenity" being another regulation especially relevant with child sexual abuse is explained as "Anyone who openly shows the content of obscene visual in places accessible or visible to children, or openly displays, exhibits them in a visible manner, reads or talks about them to children, or makes children read or talk about the content of such material, shall be imprisoned for a term of from six months to two years or a judicial fine". If legislative regulations about child sexual abuse are evaluated separately, redefined with upper caption as "child pornography" and regulated in a different article including offense act such grooming (that will mentioned below), will cause a social awareness to child abuse crimes in the perspective of community.

Grooming is described as a person who chat with child sexual content in order to prepare child abuse action. In other words, Grooming is stated that a person who gain confidence of child, meet with child and try to physical abuse with the aim of sexual exploit via IT systems, as well. This friendship address to an emotional friendship bond in order to a sexual contact. It is known also, this act is used for encouraging children to sexual activities and child pornography. Even though Grooming is accepted an offense due to reviewing as preparation movement of an offens intended for different children in various countries such as Australia, Canada, Costa Rica, Nederland and United Kingdom, unfortunately have no legislative regulation about it in Turkey.

In this context, Grooming notion has become obligatory to define and put under caption child sexual abuse in TPC with relevant articles; Sexual abuse (assault) article 103, Sexual harassment article 105, Obscenity (child-used pornographic material) article 226 and subclouse 3 .

Requirement regulations should be done to take into consideration difficulty of accumulating evidence in IT environment, and to describe situations of commit an offense and new species of offense via IT crimes. About combatting against crimes also, certainly should be cooperated with international organization which could be shared common knowledges, and should implement integration studies of Council of Europe Convention on Cybercrime to domestic law.

Specification of cybercrime necessitate to preventive and repressive measures being unique as well. Combat against cybercrimes which is exceptional qualification from conventional offenses, become indispensable with international cooperation on the purpose of coming up with suspects who might perpetrate as to connecting internet in another country with one click. Even it should not be forgotten another factor that, the center of social media web sites which are intensively used in Turkey is on foreign. Aforementioned legislative regulation should be redeployed to swiftly reach to cyber criminals without given any chance for distorting digital evidence integrity and removing offense traces. Developed countries maximize the software and hardware sets from the point of performance and security, constantly educated qualified personnels; if skilled staffs remain incapable they will benefit from having technical competence civilian in order to struggle against criminals. As of country we should pay sufficient attention to this importance detail: law enforcement officers and judicial authorities who fight against child abuse crime (that notably committed through internet and even being work item of this study), should be operative and rapidly mobilize on prevention offense and investigation stage.

On the other hand, for Turkey also more importance elements is to cooperate with international institutions such National Center for Missing and Exploited Children (NCMEC) about combatting against child abuse crimes. Briefly stated, this institution concerning about child exploit and pornography was established as a private and non-profit organization in order to protect sexual abused or missing children with congress act in 1984 in United States of America. Structurally it has investigator from law enforcement department, specialist from different institutions, psychologists and social service experts. the families also contribute to activities of NCMEC.

In current situation, NCMEC is a institution that be conveyed the prepared reports from all etection related child abuse on global service provider to proper authorities. In NCMEC, the reports of child sexual abuse namely Cyber'Tipline is conveyed by way of VPN (Virtual private network) to law enforcement departments located in different countries in the world. "Child Abuse VPNUse Policy” signed between Turkey and NCMEC in January 2014. It has been launched to get access to CyberTipline reports since 23 October 2014 and conveying numbers of 15116 reports to Turkey has been tried to determine of offense(s) and suspect(s) by law enforcement departments and judicial authorities. In this respect, thanks to vital attention of the efforts with NCMEC, should be brought to a conclusion. Because, NCMEC compile reports to shown the efforts and given importance of child abuse by countries that undertake bilateral cooperation in specific periods.

Finally, with this report indicative studies about status quo of countries is announced the world public opinion. In sum, particularly parents should take measures about misuse of social media. In this perspective, from each part of communities and each age bracket people should create awareness about how we should use social media safely in public opinion all around the world.

\section{References}

[1]. Marcum CD (2008) Identifying potential factors of adolescent online victimization for high school seniors. Intl J Cyber Criminol. 2: 346-367.

[2]. Mesch GS (2009) Parental mediation, online activities, and cyberbullying. CyberPsychology \& Behavior. 12(4): 387-393. 
[3]. Navarro JN, Jasinski JL (2012) Going cyber: Using routine activities theory to predict cyberbullying experiences. Sociological Spectrum. 32(1): 81-94.

[4]. Quayle E, Taylor M (2002) Child pornography and the Internet: Perpetuating a cycle of abuse. Deviant Behav. 23(4): 331-361.

[5]. Ubbesen MB, Gilbert R, Thoburn J (2015) Cumulative incidence of entry into out-of-home care: Changes over time in Denmark and England. ChildAbuse \& Neglect. 42: 63-71.

[6]. Alexy EM, Burgess AW, Baker T (2005) Internet offenders: Traders, travelers, and combination trader-travelers. J Interpersonal Violence. 20(7): 804811.

[7]. Webb L, Craissati J, Keen S (2007) Characteristics of Internet child pornography offenders: A comparison with childmolesters. Sexual Abuse: A Journal of Research and Treatment. 19: 449-465.
[8]. Barak A (2005) Sexual harassment on the Internet. Soci Sci Comp Rev. 23: $77-92$.

[9]. Wolak J, Finkelhor D, Mitchell KJ, Ybarra ML (2010) Online "predators" and their victims: Myths, realities, andimplications for prevention and treatment. Psychol Violence. 1: 13-35.

[10]. Mitchell KJ, Wolak J, Finkelhor D (2005) Police posing as juveniles online to catch sex offenders: Is it working? Sexual Abuse: A Journal of Research and Treatment. 17(3): 241-267.

[11]. Wolak J, Finkelhor D, Mitchell KJ (2004) Internet-initiated sex crimes against minors: Implications for prevention based on findings from a national study. J Adolescent Health. 35(5): 424.e11-424.e20.

[12]. Guide: National data archive on child abuse and neglect. National Data Archive on Child Abuse and Neglect. 